\title{
A Review on Kandilli Observatory and Earthquake Research Institute (KOERI) Seismic Network and Earthquake Catalog: 2008-2018
}

\author{
Musavver Didem Cambaz, Fatih Turhan, Mehmet Yılmazer, Kıvanç Kekovalı, Öcal Necmioğlu, and Doğan Kalafat \\ Regional Earthquake Tsunami Monitoring Center, Kandilli Observatory and Earthquake Research Institute, \\ Boğaziçi University, Çengelköy, 34684, İstanbul, Turkey
}

Correspondence: Musavver Didem Cambaz (didem.samut@boun.edu.tr)

Received: 1 June 2019 - Revised: 23 September 2019 - Accepted: 1 October 2019 - Published: 24 October 2019

\begin{abstract}
KOERI has a long history of earthquake seismology, beginning its observations right after the devastating earthquake on 10 July 1894 in Istanbul, by deploying the first seismograph in the region. Naturally, its seismic network and earthquake catalog evolved since that time, in harmony with the progress in the science of seismology. Currently, the seismic network consists of 242 stations that record approximately 1500 earthquakes per month during periods of regular seismicity. Magnitude is one of the most critical parameters in determining the size of an earthquake, especially in seismic hazard assessment studies. The objective of this study is to homogenize the magnitudes of the KOERI catalog between 2008 and 2018. For this aim, we computed the Magnitude of Completeness $\left(M_{\mathrm{c}}\right)$ for two different time periods between 2008-2011 and 2012-2018 by taking into account the duration magnitude $\left(M_{\mathrm{d}}\right)$ and local magnitude $\left(M_{1}\right)$, where these parameters might not be available jointly for the both time periods considered. As a result, we present a relationship of $M_{\mathrm{d}}$ and $M_{1}$ magnitudes derived from and applicable to KOERI's earthquake catalogs.
\end{abstract}

\section{Introduction}

Turkey and surrounding regions form one of the most seismically active regions in the world. Moderate (5.0-5.9) to strong (6.0-6.9) earthquakes occur frequently in the region, where a strong earthquake of $M>6.0$ is experienced annually or biennially, and a major earthquake of $M>7.0 \mathrm{ev-}$ ery 7-8 years. Seismicity in Turkey and its surrounding regions is monitored by a number of different establishments.
RETMC with the FDSN Network Code: KO (Boğaziçi University Kandilli Observatory And Earthquake Research Institute, 2001), is the oldest seismological observation center in Turkey monitoring the earthquake activity 24/7 (Louderback, 1948; Fettahoğlu, 2012; Kalafat, 2017; Cambaz et al., 2019). KOERI is one of the core participants and corporate founder of Observatories \& Research Facilities for European Seismology (ORFEUS) and also one of the primary nodes of the European Integrated Data Archive (EIDA), which is an initiative within ORFEUS (http://www.orfeus-eu.org/data/eida/, last access: October 2019). RETMC is also an accredited Tsunami Service Provider of the Intergovernmental Coordination Group for the Tsunami Early Warning and Mitigation System in the North-eastern Atlantic, the Mediterranean and connected seas (ICG/NEAMTWS), providing services to Eastern Mediterranean, Aegean, Marmara and Black Seas since 2012).

Seismic networks evolve in time. When dealing with an earthquake catalog, it is important to know the details of this evolution to avoid any misinterpretation of the data. Lack of information documenting the homogeneity and completeness of the data set makes it difficult to reliably interpret data. The main motivation of this study is to find a way to homogenize KOERI's earthquake catalog of different time periods and magnitude types.

\section{Seismic network}

The installation of first seismological sensor of KOERI dates back to 10 July 1894 earthquake in Marmara Region. According to the historical studies (Louderback, 1948; Fetta- 


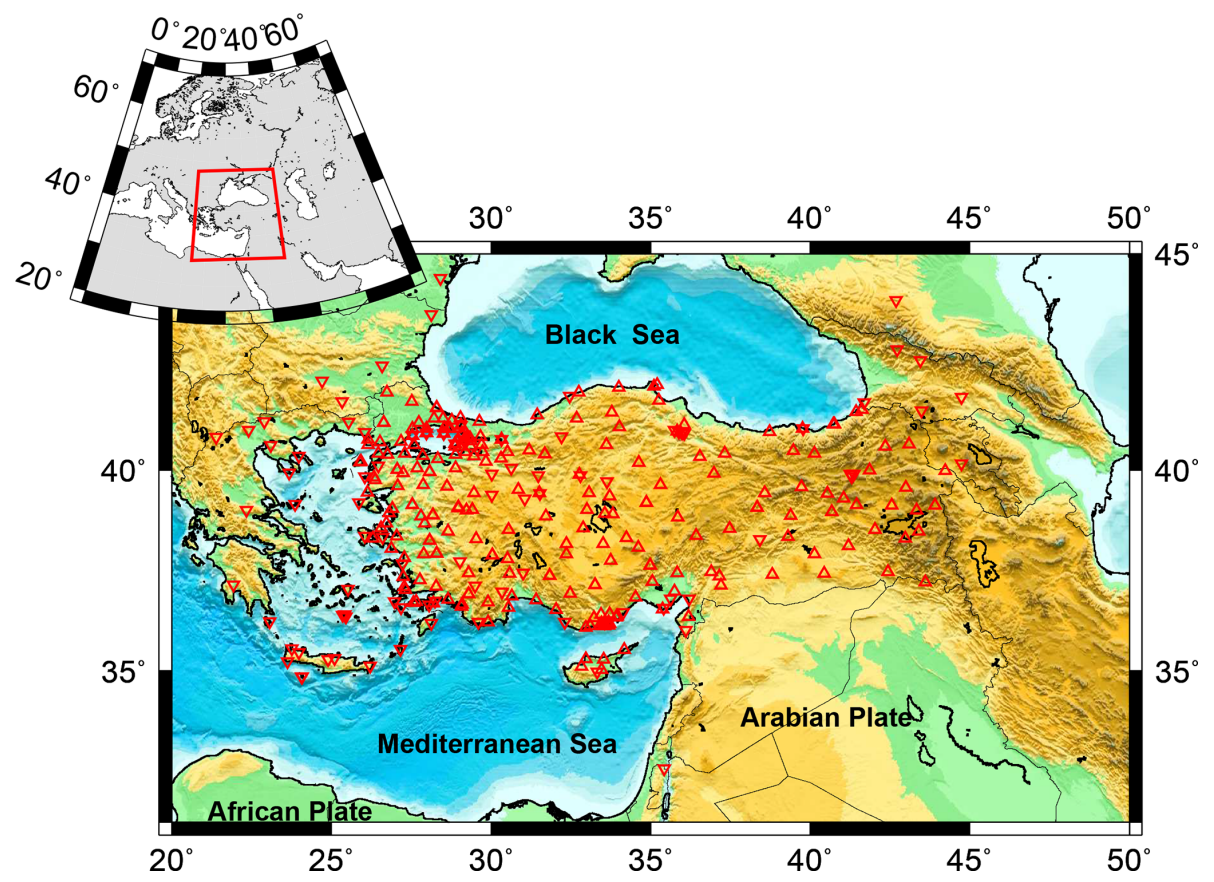

Figure 1. Station distribution used in earthquake location from RETMC network (triangles) and other stations from neighbourhood countries (reverse triangles). The red rectangle in the inset figure shows the monitoring area of KOERI-RETMC $\left(30.000-48.000^{\circ} \mathrm{N}, 22.000-\right.$ $\left.44.000^{\circ} \mathrm{E}\right)$.

hoğlu, 2012), Giovanni Agamennone came to İstanbul by the invitation of the Government of the Ottoman Empire in 1895 to study the 1894 earthquake in the Marmara region, and remained two years to install two seismographs in a specially constructed housing and to conduct relevant studies. The first mechanical station installed after this date was a Mainka seismograph, deployed in Istanbul Kandilli, where KOERI resides today, in 1938 by the government of the Republic of Turkey. KOERI's stations started to became a network starting in the early 1970's as a result of steady increase of station installations all over Turkey, growing considerably mainly after the 1999 İzmit M7.4 earthquake, accompanied also with the transition from short period stations to broadband stations, witnessing also changes in operational procedures, such as the type of magnitudes to be considered. In comparison to 35 stations in 1999, and 123 in 2010, the KOERI network consist of 242 stations today, composed of 135 broadband, 93 strong motion and 14 short period sensors (Fig. 1).

\section{Seismicity Catalog}

KOERI-RETMCs earthquake monitoring areas is confined within $30.0-48.0^{\circ} \mathrm{N}, 22.0-44.0^{\circ} \mathrm{E}$, also for the purposes of identifying any tsunamigenic earthquake in the Eastern Mediterranean and its connected Seas (Fig. 1). The recent seismicity rate is almost constant around 50 earthquakes per day during routine seismicity.
Computation of $M_{\mathrm{d}}$ from analog records had been initiated in 1992 just after the 13 March 1992 (M6.7) Erzincan earthquake. The magnitude type of the catalog was changed from duration magnitude $\left(M_{\mathrm{d}}\right)$ to local magnitude $\left(M_{1}\right)$ in 2012. However, $M_{\mathrm{b}}, M_{1}$ and $M_{\mathrm{w}}$ magnitudes are still given as reference for the important and widely felt earthquakes (Kalafat et al., 2011). High amount of quarry blasts are also recorded in the region. These events are removed regularly as a result of detailed discrimination studies based on satellite imagery, temporal and spatial properties, maximum peak amplitude ratio $(\mathrm{S} / \mathrm{P})$, power ratio, and spectral amplitude ratio of the vertical component of the seismograms (Kekovalı, 2009; Kekovalı et al., 2011, 2012; Kekovalı and Kalafat, 2014).

In this study, the area of consideration is bounded by $34.0-43.0^{\circ} \mathrm{N}, 23.0-46.0^{\circ} \mathrm{E}$, as shown in Fig. 2. Almost 200000 events were recorded in this area during the time period 1 January 2008-31 December 2018. Quarry blasts, mine explosions and other suspicious events were eliminated as mentioned above in detail (Kekoval1, 2009) and we used 174285 earthquakes for statistical analysis using ZMAP (Wiemer, 2001). Figure 3 shows the earthquake-time histogram for this between 2008 and 2018. The seismicity rate is around 1000 events per month in a period of normal seismic activity, specifically after the sharp increase in the number of stations in 2012. But an up to tenfold increase in the seismicity can also be seen after the moderate earthquakes e.g., after four moderate earthquakes $\left(M_{\mathrm{w}}=5.2\right.$ 


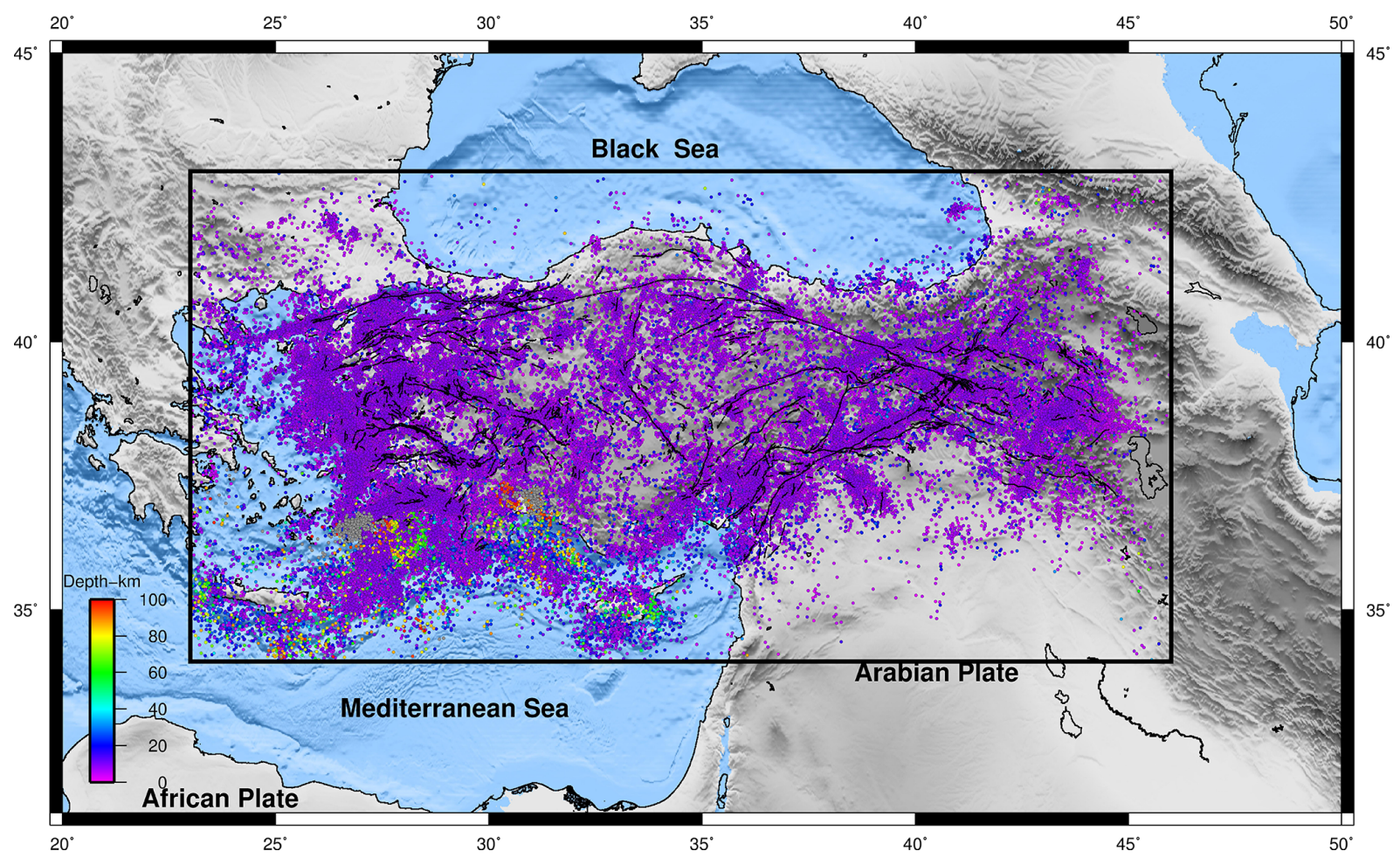

Figure 2. Seismicity map of the region with red dots representing the 174285 earthquakes recorded between 1 January $2008-31$ December 2018 and the black lines representing the active faults (Emre et al., 2013).

to $M_{\mathrm{w}}=5.4$ ) which occurred within a week in Çanakkale in February 2017, after the $M_{\mathrm{W}}=6.3$ Lesvos earthquake of 12 June 2017 and the $M_{\mathrm{w}}=6.6$ Gökova earthquake of 21 July 2017. These earthquakes were followed by an intense aftershock activity in the following months, reaching up to thousands of additional earthquakes. Figure 4 shows the depth histogram of the earthquakes between 2008 and 2018, which shows that the earthquake activity is mainly observed within 0 to $30 \mathrm{~km}$ depth with more than half of the earthquakes having hypocentral depths in the first $20 \mathrm{~km}$ of earth's crust. Deeper earthquakes generally exist at the southernwest part of Turkey along the Hellenic arc, which represents the boundary between the African and Anatolian plates in the Eastern Mediterranean Region.

\section{Comparison of Duration and Local Magnitude Catalogs}

Duration magnitude, which relies on the length of the recorded earthquake seismic coda, was the main magnitude scale used in the estimation of magnitude in KOERI prior 2012. Despite its fast and easy to use, the earthquake magnitude of consideration was changed to $M_{1}$ at the beginning of 2012 as a more scientifically sound parameter considering the needs of a national earthquake network. Currently, $M_{1}$ is used as the primary magnitude scale for the routine earth- quake magnitude estimation but $M_{\mathrm{w}}$ and $M_{\mathrm{w}} \mathrm{S}$ is also used in order to avoid the saturation problem of $M_{1}$ for earthquakes greater than 6.0.

In this study, we divided the catalog into two different time intervals corresponding to the change from $M_{\mathrm{d}}$ to $M_{1}$, namely from 1 January 2008-31 December 2011 for the $M_{\mathrm{d}}$ and from 1 January 2012-31 December 2018 for the $M_{1}$. Magnitude histograms are presented both for $M_{\mathrm{d}}$ and $M_{1}$ for a better understanding of the variation these parameters. Figure 5 shows the magnitude histogram for $M_{\mathrm{d}}$ in between 2008 and 2011. Magnitudes of earthquakes range from 1.5 to 4.5 with most of the earthquake magnitudes occurring between 2.0 to 4.0. Figure 6 shows the equivalent histogram for $M_{1}$ between 2012 and 2018. It is noticeable that $M_{1}$ varies across a wider range as compared to $M_{\mathrm{d}}$. Local magnitudes of earthquakes range from 0 to 6.0 with most of the earthquake magnitudes occurring between 1.0 to 4.0 .

\subsection{Magnitude of Completeness}

Magnitude of completeness $\left(M_{\mathrm{c}}\right)$ is a critical parameter for seismicity studies, determination of the $b$ value and seismic hazard analysis, and it can be simply defined as the lowest magnitude above which all events can be considered to be fully detected (Wiemer and Wyss, 2000). It varies as a function of space and time but also varies with artificial changes such as network configuration and magnitude esti- 


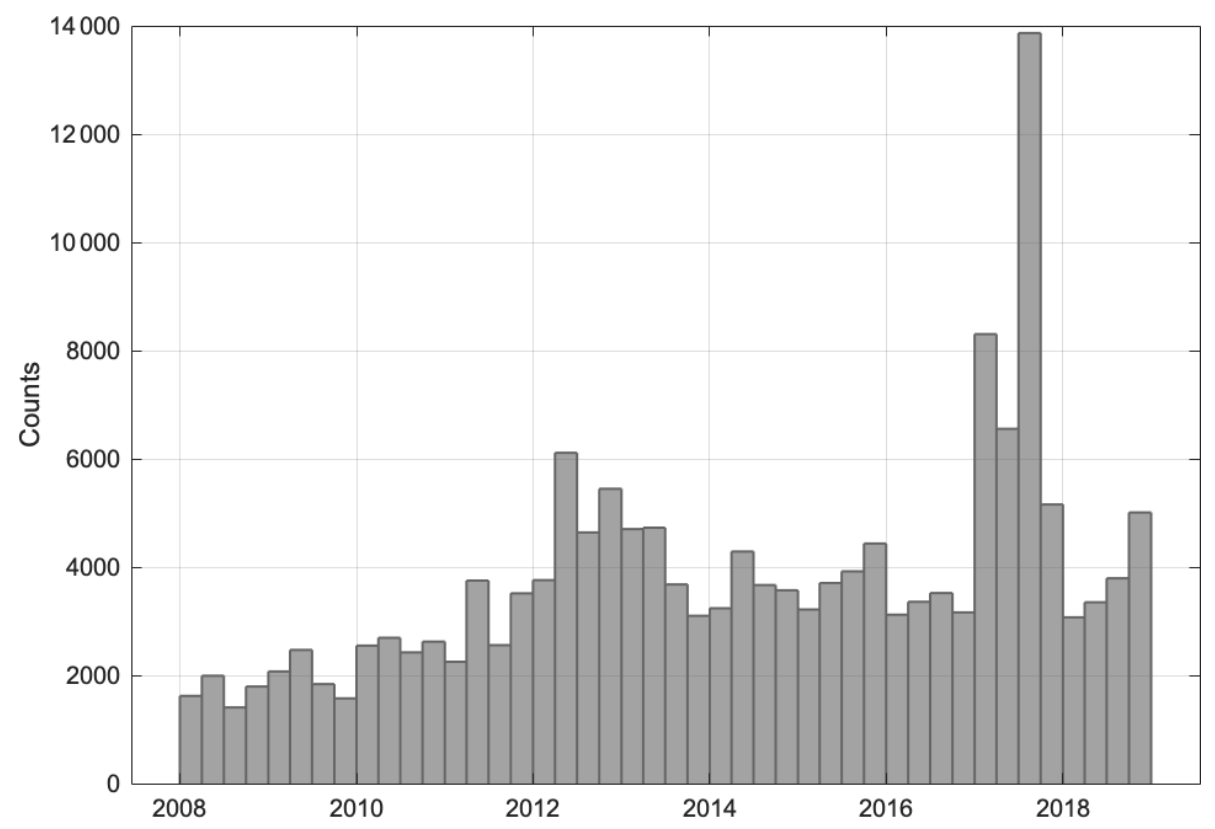

Figure 3. Earthquake - time histogram for the time interval 1 January 2008-31 December 2018.

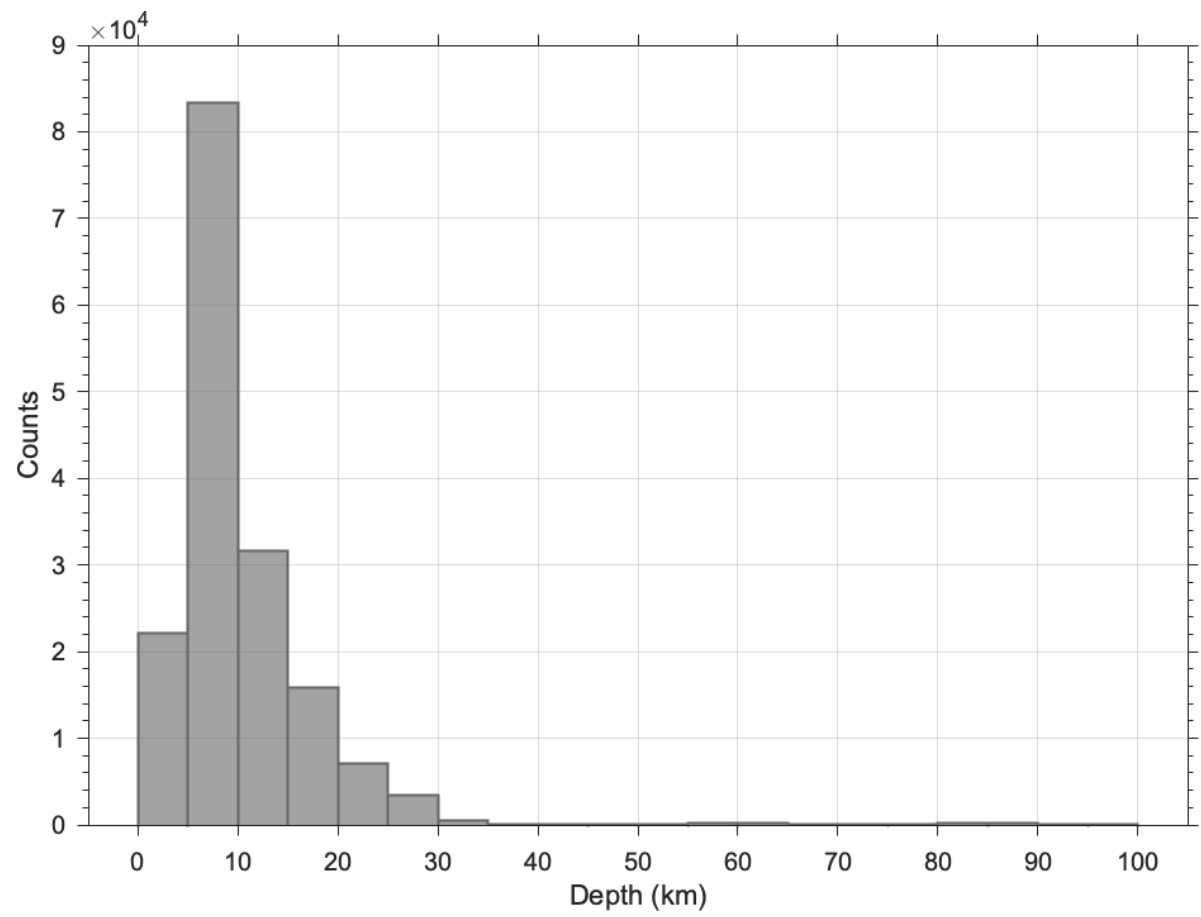

Figure 4. Earthquake - depth histogram for the time interval 1 January 2008-31 December 2018.

mation methods. $M_{\mathrm{c}}$ computation by using a maximum likelihood solution which is based on the maximum curvature method of (Wiemer and Wyss, 2000; Woessner and Wiemer, 2005) is available in ZMAP (Utsu, 1999; Wiemer and Katsumata, 1999). Maximum curvature is a fast and reliable estimate of $M_{\mathrm{c}}$, in order to define the point of the maximum curvature as a magnitude of completeness, by com- puting the first derivative of the frequency magnitude curve. This method matches the magnitude bin with the highest frequency of events in the non-cumulative frequency-magnitude distribution (Woessner and Wiemer, 2005).

Kalafat (2016) computed the $M_{\mathrm{c}}$ values of Turkey and surrounding regions by using the KOERI catalogue in the time period 1975-2015. Due to lesser number of stations during 


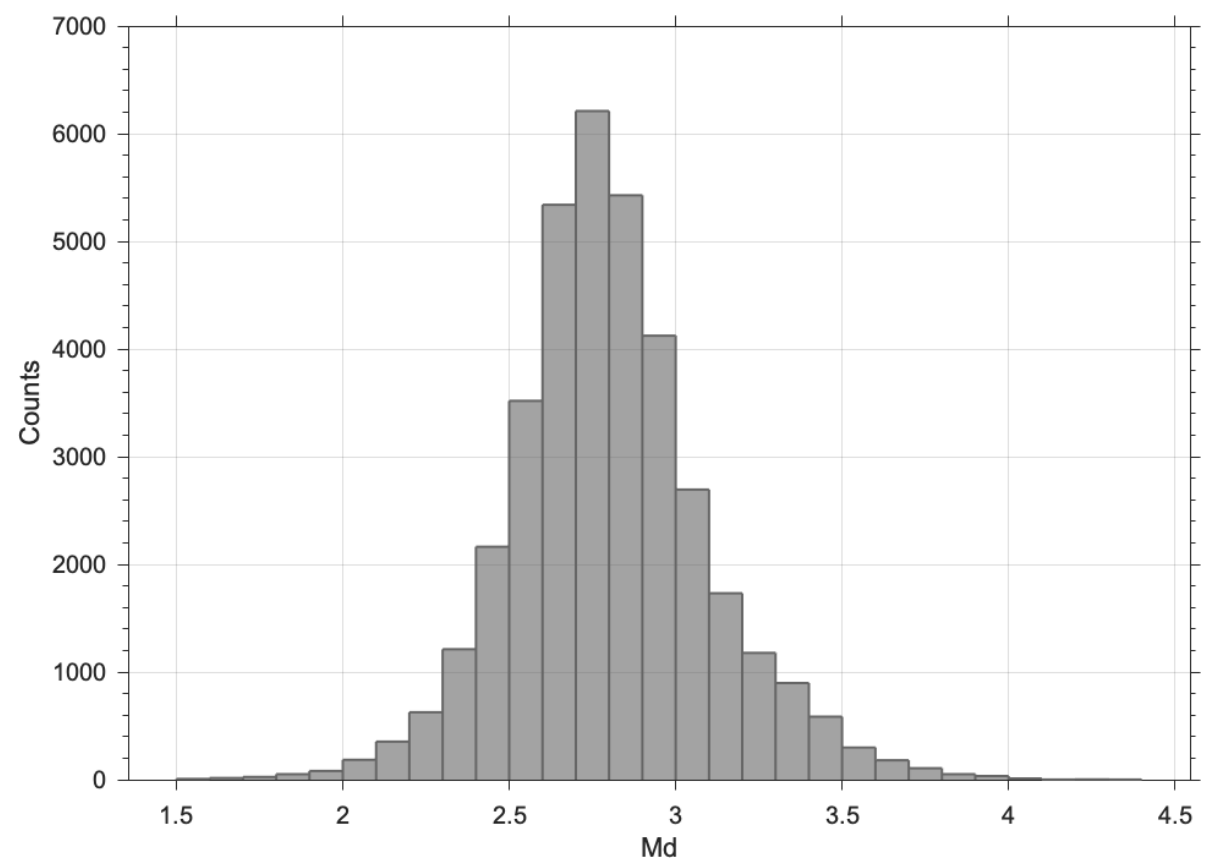

Figure 5. Earthquake - magnitude histogram of earthquakes with duration magnitude, $M_{\mathrm{d}}$, in between the time interval 1 January $2008-$ 31 December 2011.

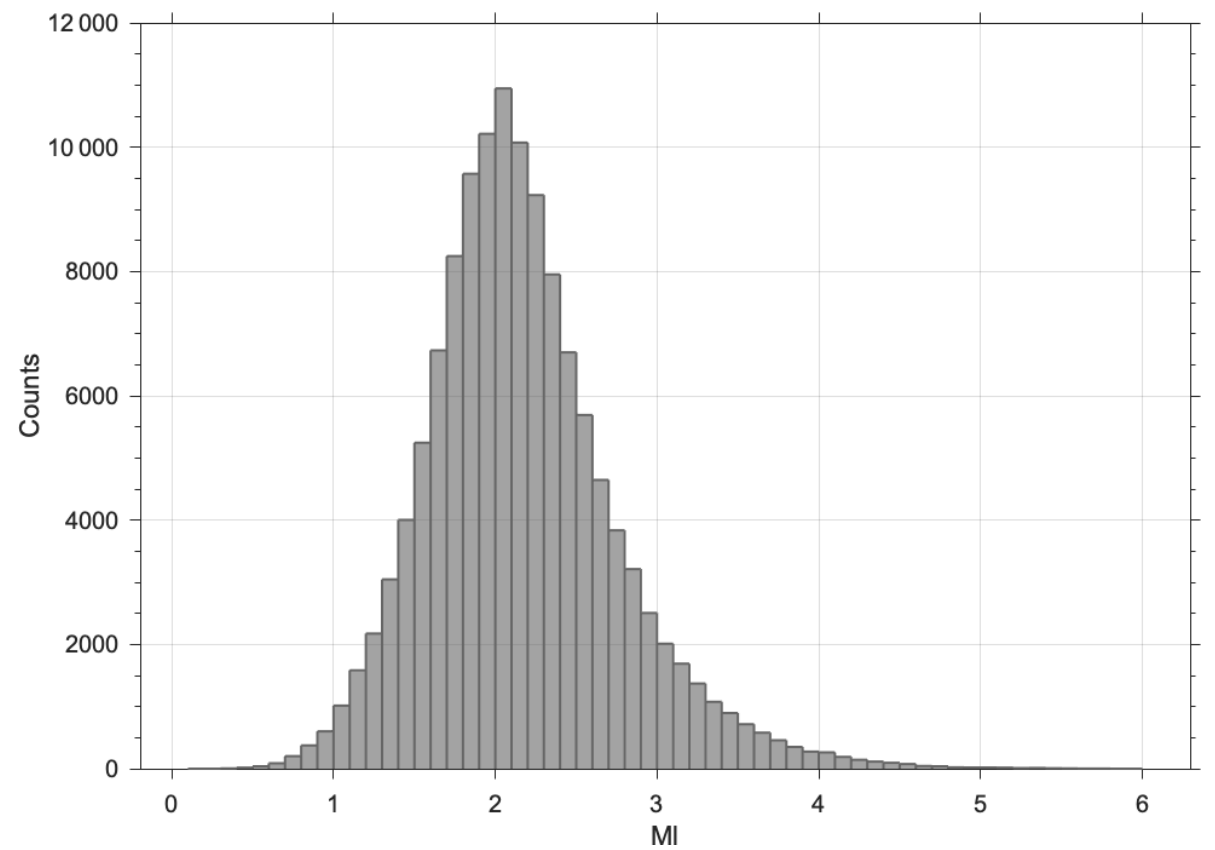

Figure 6. Earthquake - magnitude histogram of earthquakes with local magnitude, $M_{1}$, in between the time interval 1 January $2012-31$ December 2018.

the time period considered, especially in the earlier parts, Kalafat (2016) observed significantly higher $M_{\mathrm{c}}$ values in the same study area. $M_{\mathrm{c}}$ values were mainly changing between 2.6-2.9 for the selected regions. However, $M_{\mathrm{c}}$ has significantly decreased to $M_{\mathrm{c}}=2.0$ with the installation of recent stations in the study area. Cambaz et al. (2019) pre- sented the dynamic variations of $M_{\mathrm{c}}$ with respect to time and earthquakes sequences in the region for the time period 2013-2017. They computed the magnitude of completeness as $M_{\mathrm{c}}=2.0$ for almost all parts of Turkey with a $b$ value of $1.01 \pm 0.05$. They also presented the variations of $M_{\mathrm{c}}$ with time and region. 


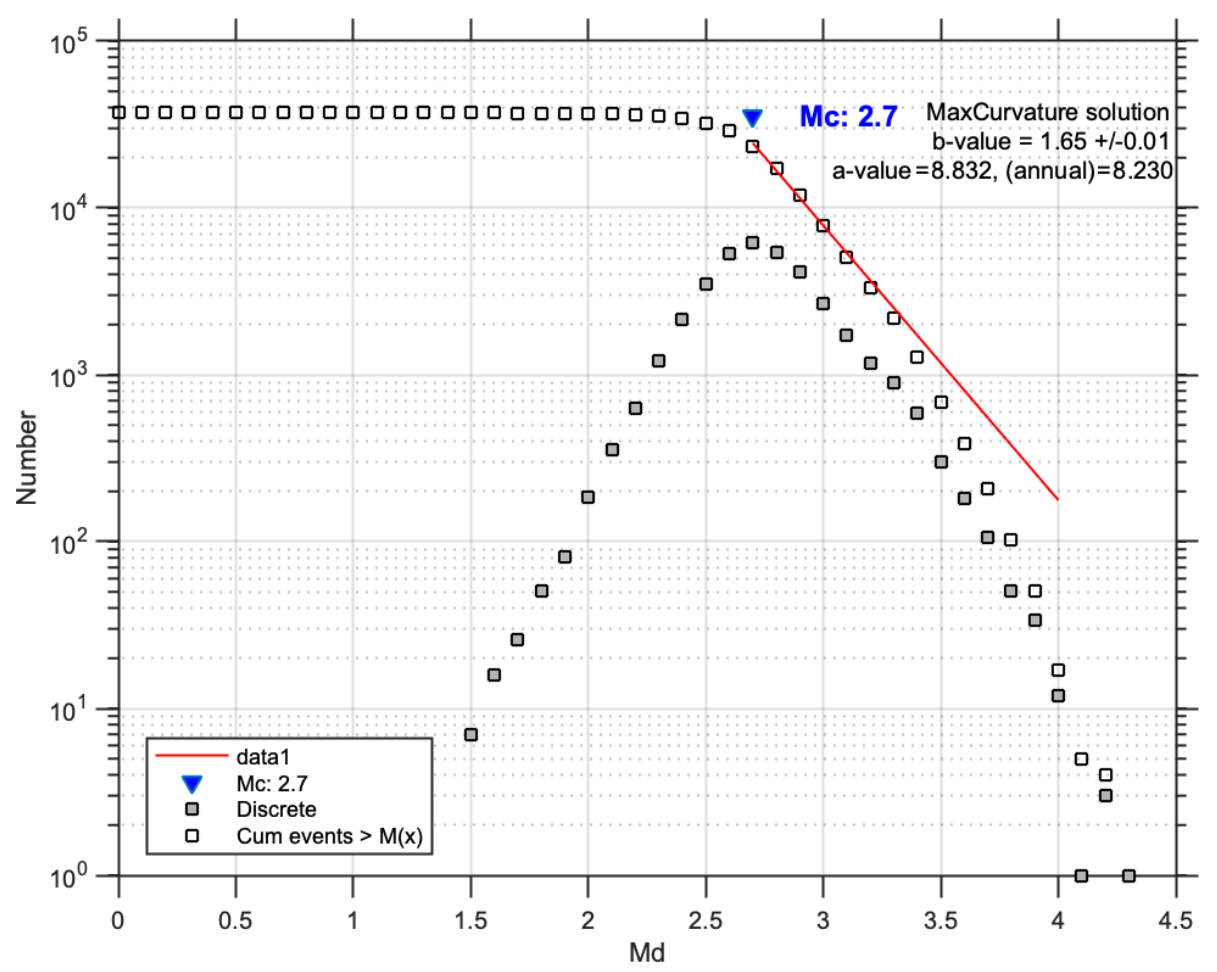

Figure 7. Frequency-magnitude distribution of the catalog in between the time interval 1 January 2008-31 December 2011 with magnitude of completeness $M_{\mathrm{c}}=2.7$.

$M_{\mathrm{c}}$ computation was performed for both of the $M_{\mathrm{d}}$ and $M_{1}$ catalog. The first period comprises almost 45000 earthquakes and the second period comprises approximately 130000 earthquakes. Figures 7 and 8 shows the frequencymagnitude distributions of the catalogs for the two different time intervals considered. We obtained a magnitude completeness $M_{\mathrm{c}}=2.7$ for earthquakes in $M_{\mathrm{d}}$ catalog and $M_{\mathrm{c}}=$ 2.0 for earthquakes in the $M_{1}$ catalog. The $M_{\mathrm{c}}=2.0$ value computed for the time interval 2012-2018 is compatible with the $M_{\mathrm{c}}$ value $\left(M_{\mathrm{c}}=2.0\right)$ obtained by Cambaz et al at a similar time interval (2013-2017). However, a significant variation between the two $M_{\mathrm{c}}$ values for the catalogs pre and after 2012 is observed, which may be related not only with the change of magnitude scale from $M_{\mathrm{d}}$ to $M_{\mathrm{l}}$, but also to network geometry. Indeed, the number of sensors operated by KOERI was 123 in 2010, but increased almost twice in number up to 2019. The number of earthquakes are quite different in the catalogs for these two different time periods. The tremendous increase in station number and hence in the number of detected earthquakes cause a drastic difference in $M_{\mathrm{c}}$ values obtained for these two catalogs. Strong variations were also observed on the computation of $b$ values, namely a $b$ value of 1.65 for the $M_{\mathrm{d}}$ catalog and 0.83 for the $M_{1}$ catalog. Variations in $b$ value can be affected by the occurrence of large events and amount of small events, generally. Also a cut off or threshold magnitude in the analysis of $b$ value usually result in higher $b$ values.

\subsection{Relationship Between $M_{\mathrm{d}}$ and $M_{\mathrm{l}}$ Catalogs}

A homogeneous database of magnitude observations is a major requirement for seismic hazard studies. In order to homogenize the catalogs, a relationship between local and duration magnitude was computed. The dataset used in this study consists of 21543 earthquakes occurring from 2008 to 2011 and selected from the $M_{\mathrm{d}}$ catalog. $M_{1}$ magnitudes were computed by using the zSacWin (Yllmazer, 2012), which is a windows-based software providing easy usage of the routine earthquake location package HYPO71 (Lee and Lahr, 1972) together with the use of Kalafat et al. (1987) crustal model for the location of earthquakes. Earthquakes computed with more than 5 stations were selected in order to obtain a reliable and trustworthy relationship. The relationship obtained as; $M_{1}=1.0313 M_{\mathrm{d}}-0.7677$ between $M_{1}$ and $M_{\mathrm{d}}$ as in Fig. 9 . As a comparison, Tuve et al. (2015) obtained a relationship between $M_{1}$ and $M_{\mathrm{d}}$ as; $M_{1}=1.164 \times M_{\mathrm{d}}-0.337$ for the Mt Etna region. Brumbaugh (1989) stated a relation between $M_{1}$ and $M_{\mathrm{d}}$ as; $M_{1}=0.936 M_{\mathrm{d}}-0.16 \pm 0.22$ in North Arizona according to their linear regression analysis.

\section{Results}

Earthquake catalogs are one of the most important products of seismological agencies. Quality, consistency and the homogeneity of the seismic catalogs must be well defined for 


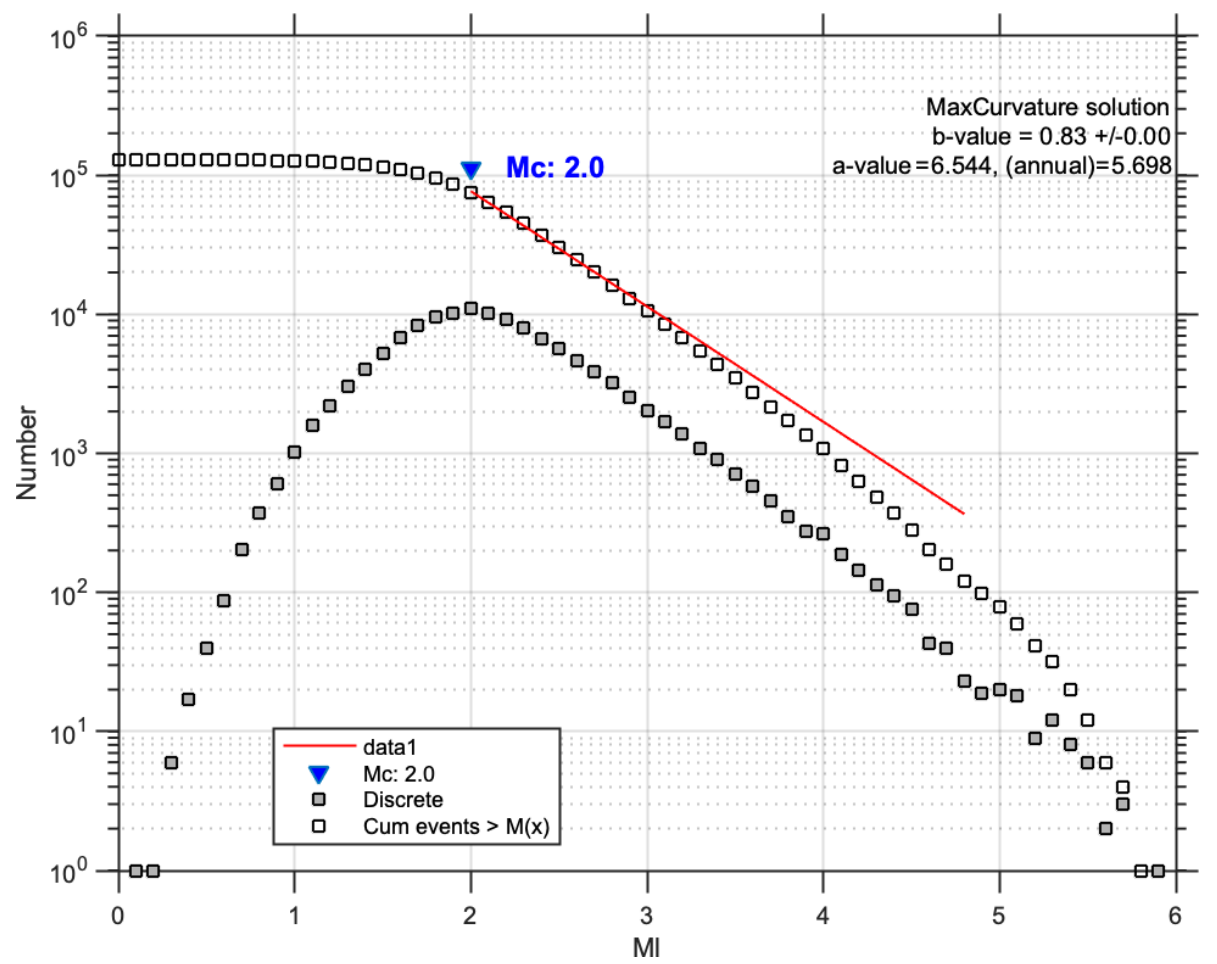

Figure 8. Frequency-magnitude distribution of the catalog in between the time interval 1 January 2012-31 December 2018 with magnitude of completeness $M_{\mathrm{c}}=2.0$.

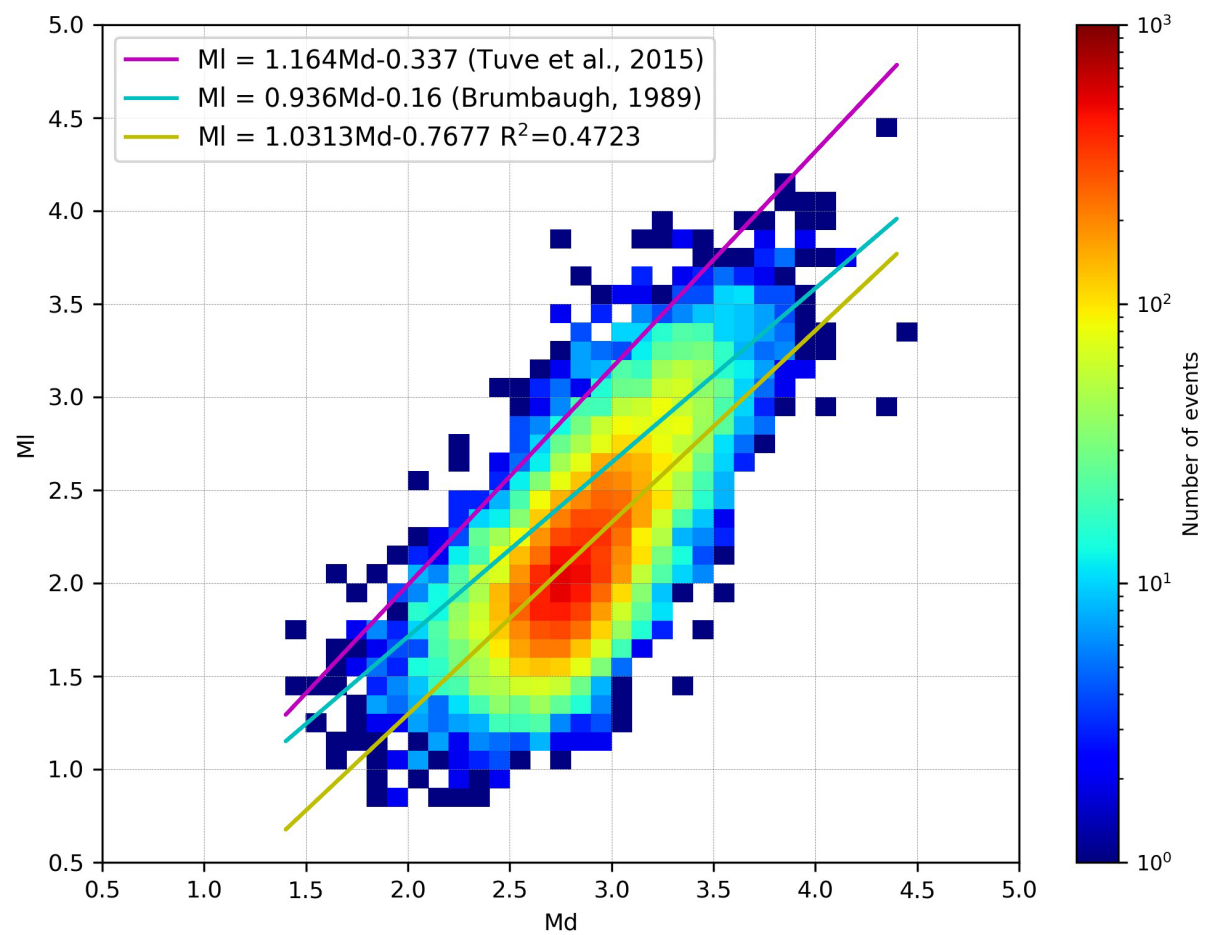

Figure 9. The relationship between $M_{\mathrm{d}}$ and $M_{1}$. 
a healthy interpretation of seismic studies. In this study we analysed the earthquake catalog in two different parts before 2012 and since 2012 by considering the types of earthquake magnitude applicable, namely $M_{\mathrm{d}}$ prior to 2012 and $M_{1}$ after 2012. We presented the statistical analysis of the catalog by plotting the $M_{\mathrm{d}}$ magnitude histogram and $M_{1}$ magnitude histogram for the selected time intervals and computed the Magnitude Completeness $M_{\mathrm{c}}$ in these two different time intervals. Magnitude of completeness was computed as $M_{\mathrm{c}}=2.7$ for the $M_{\mathrm{d}}$ catalog by using the earthquakes between 1 January 2008-31 December 2011 and $M_{\mathrm{c}}=2.0$ for the $M_{1}$ cata$\log$ by using the earthquakes in between 1 January 2012 and 31 December 2018. $b$ values were presented as 1.65 for $M_{\mathrm{d}}$ catalog and 0.83 for $M_{1}$ catalog. Differences in network status and earthquake catalogs result with strong variations in terms of $b$ value and $M_{\mathrm{c}}$. For reliable estimates of $\mathrm{b}$ and $M_{\mathrm{c}}$ values it is necessary to make use of as much data as possible and homogenization of earthquake catalogs of different types of earthquake magnitudes plays an important role for this purpose. We derive an empirical relationship between $M_{\mathrm{d}}$ and $M_{1}$ to accomplish this, which allows to back-extend the local magnitude dataset. The outcome is expected to better serve the needs of seismic hazard studies based on KOERI's earthquake catalogs.

Code and data availability. Seismicity analysis of this catalog was made by using the ZMAP software (Wiemer, 2001) which uses a number of scripts written in Matlab (http://www.mathworks.com, last access: October 2019). Some of the figures were plotted using Generic Mapping Tools (Wessel et al., 2013).

The earthquake catalog and waveform data is available via Kandilli Observatory and Earthquake Research Institute (KOERI) web page (http://www.koeri.boun.edu.tr/sismo/2/tr/, last access: October 2019, Boğaziçi University, 2019). KOERI waveform data can also be obtained through EIDA.

Author contributions. MDC, FT carried out the data analysis with the software support of MY. MDC, FT, ÖN created the figures. MY,ÖN, KK, DK evaluated the analysis. MDC prepared the manuscript, all authors read and approved the manuscript.

Competing interests. The authors declare that they have no conflict of interest.

Special issue statement. This article is part of the special issue "Improving seismic networks performances: from site selection to data integration (EGU2019 SM5.2 session)". It is a result of the EGU General Assembly 2019, Vienna, Austria, 7-12 April 2019.

Acknowledgements. This article follows from the presentation given at EGU 2019, session "Improving seismic networks perfor- mances: from site selection to data integration" and the authorship therein. In addition, we thank all staff of RETMC. We are thankful to anonymous referees and Helle Pedersen for their most valuable comments and criticism. We would like to thank the Topical Editor Damiano Pesaresi for the support provided during the review process of this manuscript.

Review statement. This paper was edited by Damiano Pesaresi and reviewed by two anonymous referees.

\section{References}

Boğaziçi University, Kandilli Observatory and Earthquake Research Institute: International Federation of Digital Seismograph Networks, Dataset/Seismic Network, https://doi.org/10.7914/SN/KO, 2001.

Boğaziçi University, Kandilli Observatory and Earthquake Research Institute, Regional Earthquake-Tsunami Monitoring Center: Waveform Data, available at: http://www.koeri.boun.edu.tr/ sismo/2/tr/, last access: October, 2019.

Brumbaugh, D. S.: A comparison of Duration Magnitude to Local Magnitude for Seismic Events Recorded in North Arizona, Journal of the Arizona-Nevada Academy of Science, 23, 29-31, 1989.

Cambaz, M. D., Turhan, F., Yılmazer, M., Kekovalı, K., Necmioğlu, Ö., and Kalafat, D.: An Investigation on the Evaluation of Seismic Network and Catalogue of Regional Earthqauke-Tsunami Monitoring Center, Yerbilimleri, 40, 110135, https://doi.org/10.17824/yerbilimleri.500472, 2019.

Emre, Ö., Duman, T. Y., Özalp, S., Elmacı, H., Olgun, Ş., and Şaroğlu, F.: Active Fault Map of Turkey, General Directorate of Mineral Research and Exploration, Ankara, Türkiye, 2013.

Fettahoğlu, K.: Rasathane-I Amirenin Kuruluşu ve Faaliyetleri (1868-1922), Yüksek Lisans Tezi, Marmara Üniversitesi, 2012.

Kalafat, D.: Statistical Evaluation of Turkey Earthquake Data (1900-2015): A Case study, Eastern Anatolian Journal of Science, 12, 14-36, 2016.

Kalafat, D.: Türkiye'de Sismik Gözlem Ağlarının Gelişimi, (Tema Konuşması), 4: Ulusal Deprem Mühendisliği Konferansı, Eskişehir, Turkey, 11-13 Oktober, 2017.

Kalafat, D., Gürbüz, C., and Üçer, B.: Batı Türkiye'de Kabuk ve Üst Manto Yapısının Araştırılması, Deprem Araştırma Bülteni, 59, 43-64, 1987.

Kalafat, D., Güneş, Y., Kekovalı, K., Kara, M., Deniz, P., and Yılmazer, M.: Bütünleştirilmiş Homojen Türkiye Deprem Kataloğu, Boğaziçi Universitesi, Bebek, İstanbul, 2011.

Kekovali, K.: Patlatma Kaynaklı Verilerin Deprem Verilerinden Ayrımına Yönelik Spektral Yöntemlerin Uygulanabilirliği ve Patlatma Veri tabanı Katalog Hazı rlı ğı, Boğaziçi University, Scientific Research Projects (BAP), Number 09T202P. 2009.

Kekoval1, K. and Kalafat, D.: Detecting of Mining-Quarrying Activities in Turkey Using Satellite Imagery and Its Correlation with Daytime to Night-time Ratio Analysis, J. Ind. Soc. Remote Sens., 42, 227-232, https://doi.org/10.1007/s12524-013-0281-4, 2014.

Kekovali, K., Kalafat, D., Kara, M., and Deniz, P.: The estimation capability of potential mining and quarry areas from seismic cat- 
alog using statistical analysis, an application to Turkey, Int. J. Phys. Sci., 6, 3784-3794, 2011.

Kekoval, K., Kalafat, D., and Deniz, P.: Spectral discrimination between mining blasts and natural earthquakes: Application to the vicinity of Tunçbilek mining area, Western Turkey, Int. J. Phys. Sci., 7, 5339-5352, https://doi.org/10.5897/IJPS12.156, 2012.

Lee, W. H. K. and Lahr, J. C.: HYPO71: A Computer Program for Determining Hypocenter, Magnitude and First Motion Pattern of Local Earthquakes Open File Report, US Geological Survey, 100 pp., https://doi.org/10.3133/ofr72224, 1972.

Louderback, G. D.: Giovanni Agamennone, B. Seismol. Soc. Am., 38, 289-290, 1948.

Tuve, T., Damico, S., and Giampiccolo, E.: A new $M_{\mathrm{d}}-M_{1}$ relationship for Mt. Etna earthquakes (Italy), Ann. Geophys., 58, S0657, https://doi.org/10.4401/aq-6830, 2015.

Utsu, T.: Representation and Analysis of the Earthquake Size Distribution: A Historical Review and Some New Approaches, Pure Appl. Geophys., 155, 509-535, https://doi.org/10.1007/s000240050276, 1999.

Wessel, P., Smith, W. H. F, Scharroo, R., Luis J. F., and Wobbe, F.: Generic mapping tools: improved version released, EOS Trans. AGU, 94, 409-410, 2013.
Wiemer, S.: A Software package to Analyze Seismicity: ZMAP, Seismol. Res. Lett., 72, 373-382, 2001.

Wiemer, S. and Katsumata, K.: Spatial variability of seismicity parameters in aftershock zones, J. Geophys. Res., 104, 1313513151, https://doi.org/10.1029/1999JB900032, 1999.

Wiemer, S. and Wyss, M.: Minimum magnitude of complete reporting in earthquake catalogs: Examples from Alaska, the Western United States, and Japan, Bull. Seismol. Soc. Am., 90, 859-869, https://doi.org/10.1785/0119990114, 2000.

Woessner, J. and Wiemer, S.: Assessing the Quality of Earthquake Catalogues: Estimating the Magnitude of Completeness and Its Uncertainty, Bull. Seism. Soc. Am., 95, 684-698, https://doi.org/10.1785/0120040007, 2005.

Y1lmazer, M.: zSacWin: A Rapid Earthquake Processing and Archiving System, User Guide v1.0, December 2012, Supported by the Research Fund of the Boğaziçi University Project Number 5725P, 2012. 